\title{
Technology- A Firm Foundation for Entrepreneurship
}

\section{Shashi Prabha Nagendra}

Assistant Professor, Department of Training and Placement, BNM Institute of Technology, Bangalore, India

Received: 08 Sept 2020; Received in revised form: 16 Nov 2020; Accepted: 23 Nov 2020; Available online: 07 Dec 2020

(C)2020 The Author(s). Published by Infogain Publication. This is an open access article under the CC BY license

(https://creativecommons.org/licenses/by/4.0/).

\begin{abstract}
A high quality education and an innovative idea impart support to entrepreneurs. However, a technically supported business can have a global impact and thrive in the growing competition.

Today, due to globalization the trends of business have changed. A touch of technology in business accelerates the success. Our education today provides excellent experience anda congenial platform for learners to take their learning beyond books and employment. In addition to this progress, the millennials possess passion and energy required for entrepreneurship. The integration of the right education and enthusiasm from learners forms a pillar for entrepreneurship. However, this pillar cannot be strong enough if it is not based on the right technology suited for the business. Hence, we have been witnessing the collapse of small businesses managed by the people who are ignorant of the industry vertical. This paper focuses on the integration of technology and modern educational background that can form a firm basis for entrepreneurs. The role of AI, ML and Blockchain can bring a cornucopia of benefits for the neophytes in the business domain. This survey focuses on three different respondents who adopted technology to save their business from collapsing. This paper also provides a solution for revolutionizing and propelling the ecosystem of the startup companies. This will improve the cost of operation and fetch high revenue.
\end{abstract}

Keywords-Business Vertical, Ecosystem, Entrepreneurship, Sustainability, Technology.

\section{INTRODUCTION}

Entrepreneurs are the brave hearts; they are constantly looking at improving their efficiency of operations by being willing to adopt new technologies, and they hope to be recognized someday in their journey toward being successful in establishing a company. This paper focuses on how entrepreneurs across an industry vertical have journeyed to adopt emerging technologies like Artificial intelligence (AI), and Blockchain to stay ahead of the competition and hope to bring returns on their investment in the near future. These technologies although relatively new, have gained immense popularity at an exponential pace. According to Gartner reports $^{1}$, AI and Blockchain are among the top 10 strategic technology adoptions for the coming years as illustrated in Figure 1.Competitive businesses are actively investing in latest technologies to deliver great customer service. This paper discusses how three entrepreneurs, respondent of a survey, chose to adopt technical tools and save their business from becoming obsolete. Adopting technology has helped the three entrepreneurial firms to improve their efficiency of operations, and revenue over a period.

\subsection{Statement of the Problem}

Entrepreneurs, though educated, are unaware of the appropriate technology that can enhance their business by addressing the challenges. The mentioned technologies can be adopted for future projects.

\section{OBJECTIVES OF THE STUDY}

- To create awareness on the fact that adopting the appropriate use of technology can sustain a business. 
- To highlight the fact that, as finance can be a challenge, it is possible for entrepreneurs to take nimble steps when adopting technology in their business.
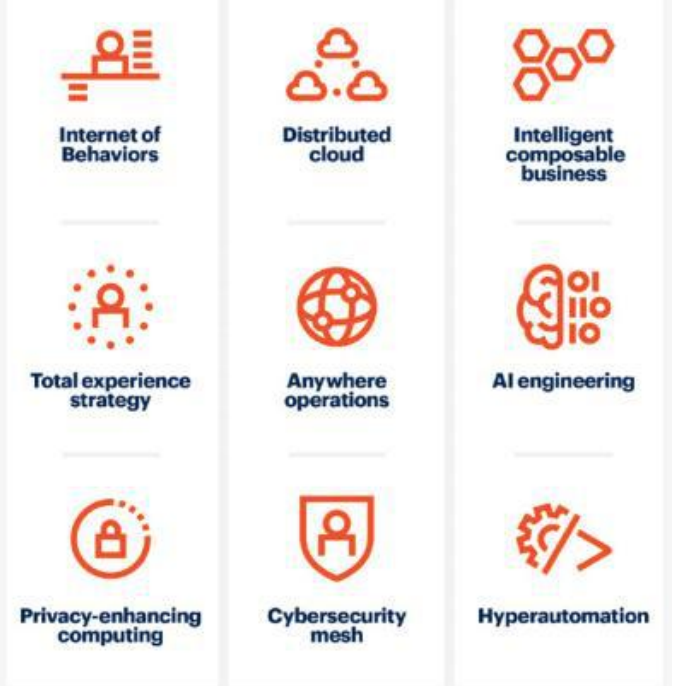

Fig. 1: Top 10 strategic technology trends in 2020

Source: Gartner [2]

\section{TECHNOLOGY ADOPTION CASE STUDIES}

Entrepreneur A, chose to adopt technology and reboot the company

\subsection{Artificial Intelligence Applications}

\subsubsection{Grammarly AI Application}

The startup company established by Entrepreneur A, focused on Mobile and Cloud application development and services business. An interview with the entrepreneur revealed that the company faced challenges due to the inadequate communication skills of the employees. The fresh engineering graduates from tier 3 and 4 colleges, had a strong influence of their native language. These employees had a command over technical skills but lacked effective business English communication skills.

The company lost valuable time in understanding the communique of these employees as they used improper English grammar and incomplete sentences which made it hard for the management to understand project documents and emails. This led to miscommunication and losing of valuable clients. Missing project deadlines meant that the productivity of the company was hampered.

The issue related to communication skills could not be ignored and became more important as there was a need to communicate clearly and effectively with company management and clients overseas. Additional expense and time spent on providing employees with a workshop would be futile for a startup. An Artificial Intelligence online tool explored to improve the effectiveness of communication between the management and the employee, proved to be conducive. Funds and Resources are a cause of concern for startups. Therefore, the firms highlighted here, took nimble steps to gain access to the appropriate technology.

An AI tool called "Grammarly", which is an online application powered by Machine learning algorithms recognizes stylistic and semantic errors, wrong sentence structure, and other nuanced language features [1]. The content generated can be uploaded to "Grammarly" which is hosted in the public cloud to analyze and make suggestions for corrections. The freemium service was chosen by the company initially to get a feel for the AI tool. The tool proved to be simple and effective to produce documents with almost no grammatical errors. This saved the company time and energy to focus on new initiatives. In addition to this, it instilled confidence in the employees to correspond directly with clients. Better communication fetched better results.

The employees benefit to a great extent from this tool as AI analyzes each sentence and provides options to improve the sentence, whether it's correcting a verb tense, offering a clearer sentence structure or suggesting a stronger synonym. "Grammarly" also provides contextual awareness, needed for the company's progress.

The management of the startup company also decided to try the premium service of "Grammarly" for a limited time to help with plagiarism checking for the creation of technical documents, white papers and product collaterals. "Grammarly" saved the company several weeks of time on mundane tasks of checking email and documents, which play a very important role when communicating with external clients.

\subsubsection{Tetra AI Application}

Another challenge that Entrepreneur A faced was the sales and marketing of the company products done over the telephone to rope in new clients. Employees faced difficulty in speaking and writing simultaneously over the phone and left out important details. An APP called "Tetra" helped ease this stress. "Tetra" recorded notes during the conversation and presented it in the written form for reference. The notes available could be shared later with the 
management. A sample illustration is shown below in Figure 2.

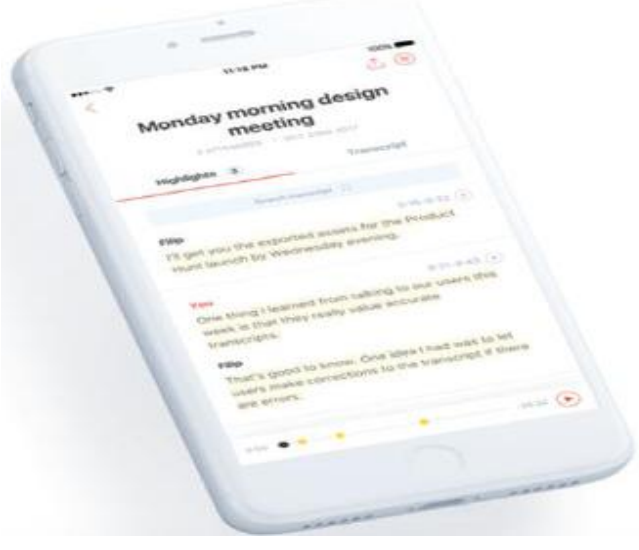

Fig. 2: Tetra audio to text capture

Source: Tetra

As illustrated in Figure 3, the company initially spent almost $20 \%$ of their time in fixing communication gaps, but as time progressed the percentage of time dropped to about $5 \%$ in a span of six months. This translates to substantial savings for the company.

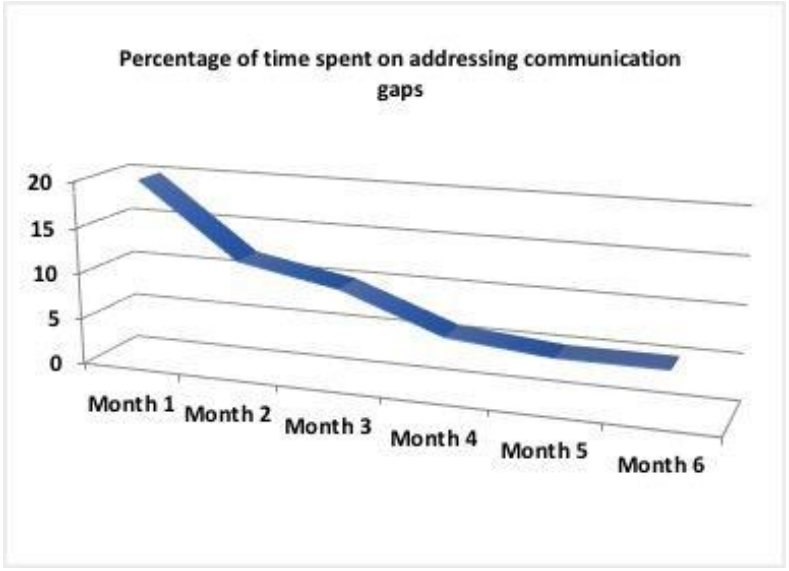

Fig. 3: Cost reduction using AI tools - Grammarly and Tetra

\subsubsection{Eurabot AI application- Maximizing growth through technology}

Entrepreneur B, the second startup company is in fine dining restaurant business focused on Italian cuisines and is currently profitable. During weekends and lunch hours the seating being limited, led to long wait hours for customers that was agonizing. This in turn led to negative customer reviews. The management explored AI tools, which reduces the need for interaction with the management staff during wait times. The trend as per Gartner reports, speaks about the growing need for less human interaction to increase customer satisfaction. This is taken care by "Chatbots" which is a computer application powered by artificial intelligence to communicate with humans.

One such intelligent "Chatbot" developed by a local IT company for the restaurant named, "Eurabot" and is supported on Android devices. "Eurabot" requires Internet connectivity and communicates with the web application hosted in the cloud. This is developed specifically for the restaurant needs.

Technology has indeed provided a stable form for business. Customers waiting to be seated have the option of using the "Eurabot" running on an Android tablet to answer questions on a variety of commonly asked questions, which the AI system in the cloud is trained to perform. Some of the sample features provided are: the customer's choice of cuisine which is suggestive based on variety of dishes and options that pop up matching with the customer's choice. For example, if a customer selects Pasta, Salads or Pizza, the application gives options like - Veg or Non-Veg, Spicy or Mild. Each category has sub menu items, like if Pasta is chosen, the type and the sauce requirement is suggested. A suggestive drink to go along with the main course is also recommended such as Wine, Beer, Juices, and Mocktails. Suggestive side dishes to be selected from Breads and Salads are prompted. In other words, the prompted options make it easier for the customer to place an order without raking the brains and wasting the time on placing orders.

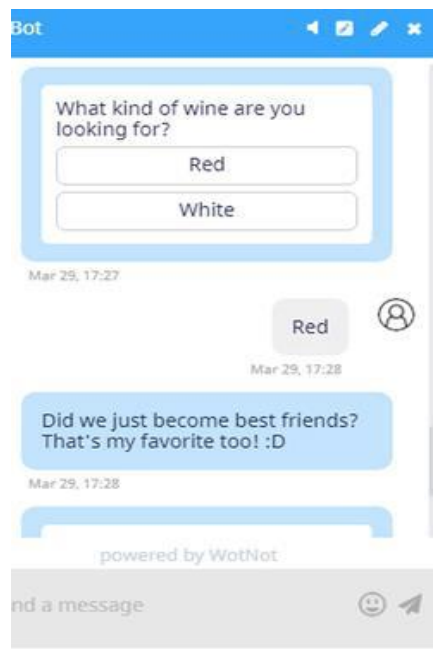

Fig.4: Sample screenshots of the Chatbot Source: dailyhunt 
The customer can place the order as shown in Figure 4, during the wait time using the "Eurabot". The phone number of the customer is recorded to make intelligent suggestions based on the past and other statistical information gathered over time.

The company saved on labor costs and time using the "Eurabot", and the application provided an insight to the management on the ordering statistics. The Analytics tool provided on the web application gave a deep dive into the patterns and time of day information. For example, the management could know the most popular Veg and NonVeg dish ordered on the weekends.

The above analytics coupled with the fact that the customer could get what he required using the "Eurabot" with minimum or no human intervention lead to improved customer satisfaction and higher revenues as illustrated in Figure 5 .

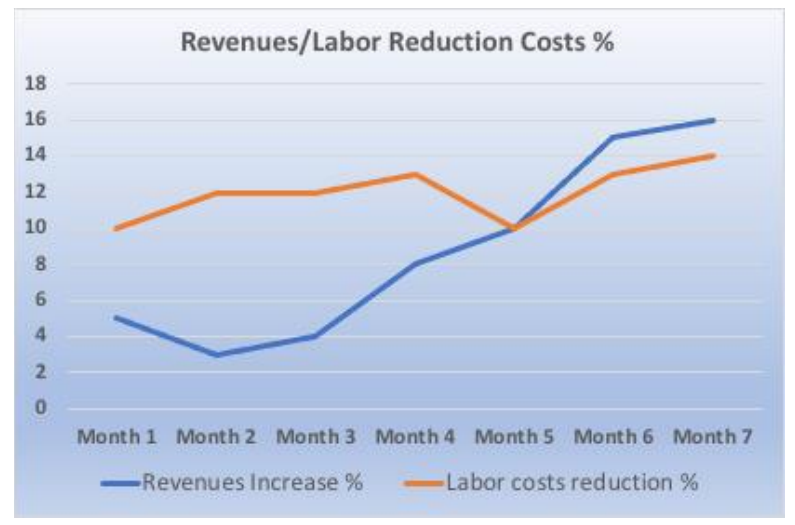

Fig.5: Cost reduction and revenue increase at restaurant

\section{BLOCKCHAIN APPLICATIONS}

\subsubsection{SynchroLife application- Gaining a competitive edge}

The restaurant startup run by Entrepreneur B, expanded their operations to Sri Lanka due to Sri Lanka's cheap labor costs and international presence. A franchisee in Colombo suburb, attracts a number of foreign tourist visitors. Since Blockchain cryptocurrency set up in Sri Lanka has no regulations, the application adopted, rewards clients based on their feedback by using the latest technologies such as AI and Blockchain. The restaurant avails the hottest Blockchain app called "SynchroLife". This application is provided to customers on Android and iOS platforms.

The social restaurant review platform offers Blockchain based token rewards to customers for high quality reviews of restaurants. Clients receive "SynchroCoin" tokens for restaurant surveys, food and restaurant photographs that they share on the portal [3].

"SynchroLife" tokens as illustrated in Figure 6, are used to remunerate food, purchase computerized restaurant coupons, pay for suppers at partnered restaurants, and pay for advertising within the platform. Because of its decentralization, "SynchroLife" effortlessly stays aware of changing information regarding restaurants, including new restaurants opening and old ones closing.

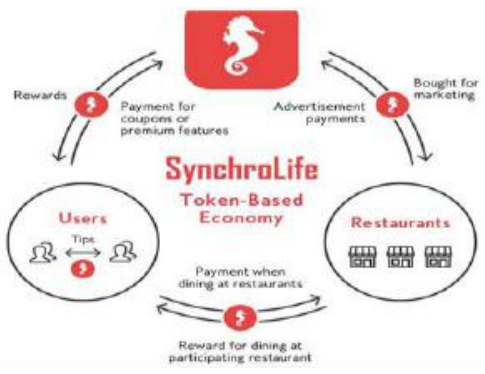

Fig.6: SynchroLife Cycle source: SynchroLife

The token-based economy keeps commentators compensated when they make a meaningful contribution to the platform. This places, an incentive on every individual's input and furthermore urges him to continue sharing exact, dependable information in addition to original substance. With the token-based economy, clients are urged to continue using the platform and enable it to develop. This has helped the restaurant stay above technology and envision a manifold growth. Artificial Intelligence customizes individual needs and displays the suggestions. Rewards and tokens for participation, provides customers an opportunity to stay connected with the business [3].

\section{ENGO AI APPLICATION}

Entrepreneur C, the third startup runs a retail store specializing in Stationary supplies for office and schools, Xerox services and other miscellaneous transactions. The startup located in the prime vicinity of schools and shopping remains swamped with customers during the peak hours. Increasing the workforce would mean an additional cost and facing daunting challenges in retaining the workforce. The company in two years had not broken even. The power of technology provided a firm base. 
The entrepreneur came across an idea of developing a simple e-commerce website with chat-bot-web widget integration. An Intelligent "Chatbot" suitable for the Indian retail market was identified. The "Chatbot" is made available on their retail website for customers to interact, find their needs and place their orders.

The company used retail "Chatbot" called "engo", as it does not require any app installation on the mobile device, and saves clutter on the mobile device. The "engo" responsive web application is hosted in the cloud, and can be accessed from any mobile device. Customers were shown how to look up and ask questions to "engo" and also place order online to pick up later at the store. Xerox information can be placed using "engo", such as number of copies, double-sided or single-side, collated, stapled etc. and time of pick up. Customers can share their purchase of products and experiences with other friends using social sharing features. This technology has helped the retail store gain more business as customers prefer picking their orders at their convenience.

The company's revenue increased steadily over a period of six months, as well as the customer satisfaction, which is a key indicator for growth as illustrated in Figure 7.

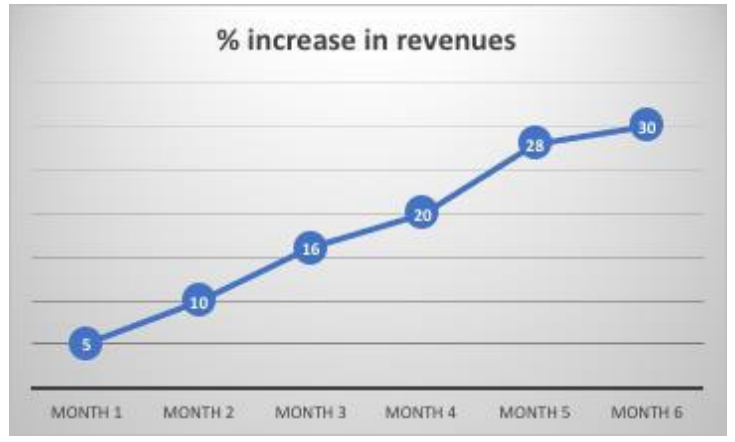

Fig.7: Revenues over six month period

\section{RESULTS}

From this study, we can state that technology forms a firm foundation for a stable business:

Based on the findings, it can be suggested that an AI Platform be developed to connect entrepreneurs with the technology specialist to address the challenges. Entrepreneurs can also get to know what technology fits their requirements from the experience of other entrepreneurs signed up with the AI Platform. Engineering students can sign up on the AI platform and mention their skill sets. AI platform will identify students possessing niche skills that entrepreneurs are looking for. This way, the entrepreneurs who are not financially stable can get the support of technology in a cost effective way and also help the students attain visibility and recognition.

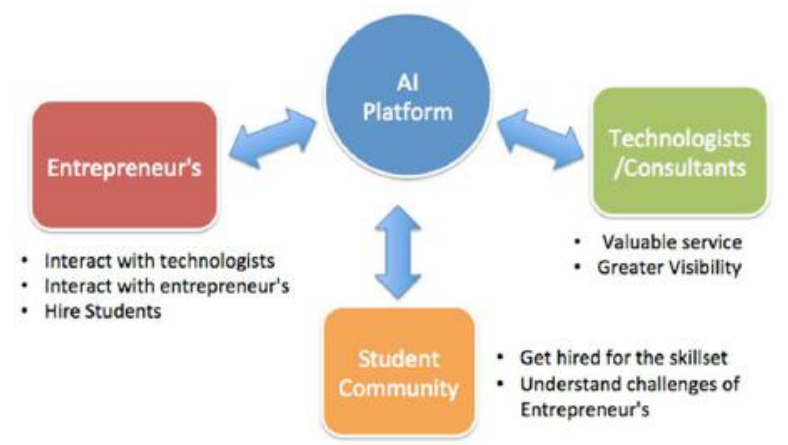

Fig.8: AI Platform for collaboration of students, consultants and Entrepreneurs

\section{CONCLUSION}

Entrepreneurs agree to the fact that Artificial Intelligence and Blockchain concord significant returns on investment by improving customer satisfaction and hence sustaining the business. These technologies provide quality customer service, engagement and satisfaction. The popularity of the technical tools has grown rapidly as customers find it convenient to use it anytime and anywhere. From the data provided, it is evident that the entrepreneurs can sustain their business even in terse conditions, with the timely and appropriate choice of technology. Awareness and knowledge of the technical tools and its advantage provided tremendous support to entrepreneurs. With the use of simple applications like Grammarly, Chatbot and SynchroLife, the entrepreneurs could save their business that was on the verge of being fading.

To conclude, it can be said that an entrepreneur can take his business to the zenith by gaining education on management skills, amalgamated with technology.

\section{LITERATURE REVIEW}

'The Upstairs' by Brad Stone [4], the internet and research journals on entrepreneurship kindled the idea of sustainability in the field of entrepreneurship. The respondents of the survey strengthened the findings and gave momentum to the development of this content. 


\section{ACKNOWLEDGEMENT:}

I would like to thank Professor, Shri Narayan Rao R Maanay- Secretary BNMEI and the management team of BNM Institute of technology for the immense support and encouragement. My gratitude also goes out to the HOD of Training and Placement Dr. Saritha Chakrasali for the motivation she has provided.

My spouse Mr. Nagendra Makam, and my two sons provide unflinching support in all my endeavors. I am obliged to them. I feel indebted to my well-wishers for their positive vibes that helps me in my writing endeavors.

\section{REFERENCES}

[1] Entrepreneur India https://www.entrepreneur.com/article/ 298628

[2] Gartner Top Strategic Technology Trends for 2021 https://www.gartner.com/en/publications/top-tech-trends2021

[3] Statrader https://statrader.com/synchrolife-review-synchrocoin/

[4] The Upstarts by Brad Stone, April 5, 2018 